\title{
Treatment techniques to reduce cardiac irradiation for breast cancer patients treated with breast-conserving surgery and radiation therapy: a review
}

\author{
Robert E. Beck, Leonard Kim, Ning J. Yue, Bruce G. Haffty, Atif J. Khan and Sharad Goyal * \\ Department of Radiation Oncology, Rutgers Robert Wood Johnson Medical School, Rutgers Cancer Institute of New Jersey, New Brunswick, NJ, USA
}

\section{Edited by:}

John Varlotto, University of

Massachusetts Medical Center, USA

Reviewed by:

Jaroslaw T. Hepel, Brown University,

USA

John Varlotto, University of

Massachusetts Medical Center, USA

*Correspondence:

Sharad Goyal, Department of

Radiation Oncology, Rutgers Cancer

Institute of New Jersey, 195 Little

Albany Street, New Brunswick, NJ

08903, USA

e-mail:goyalsh@rutgers.edu
Thousands of women diagnosed with breast cancer each year receive breast-conserving surgery followed by adjuvant radiation therapy. For women with left-sided breast cancer, there is risk of potential cardiotoxicity from the radiation therapy. As data have become available to quantify the risk of cardiotoxicity from radiation, strategies have also developed to reduce the dose of radiation to the heart without compromising radiation dose to the breast. Several broad categories of techniques to reduce cardiac radiation doses include breath hold techniques, prone positioning, intensity-modulated radiation therapy, and accelerated partial breast irradiation, as well as many small techniques to improve traditional threedimensional conformal radiation therapy. This review summarizes the published scientific literature on the various techniques to decrease cardiac irradiation in women treated to the left breast for breast cancer after breast-conserving surgery.

Keywords: breast cancer, radiation, heart, dosimetry, cardiotoxicity

\section{INTRODUCTION}

The American Cancer Society estimates that in 2014 about 232,000 new cases of invasive breast cancer will be diagnosed, as well as 62,500 cases of breast carcinoma in situ (1). The majority of these women will receive breast-conserving surgery followed by radiation. Breast irradiation has been shown to decrease the risk of local recurrence after breast-conserving surgery with few adverse effects (2). One of the most concerning complications of breast radiotherapy is cardiotoxicity from radiation to the heart.

Early studies showed decreased left ventricular function in breast cancer patients treated with radiation (3). Excess risk of cardiac mortality due to radiation, from two European randomized trials involving five different techniques, has been estimated to be $1.8 \%$ (4), though this data also suggested that only heart doses greater than 30 Gray (Gy) were important to calculate risk of cardiac toxicity. Cardiotoxicity is most frequently reported as decreased myocardial function or coronary artery disease (also reported as ischemic heart disease or decreased cardiac perfusion). However, less common toxicities can include myocardial infarction, congestive heart failure, pericarditis, arrhythmias, angina, or valve dysfunction $(5,6)$. While generalized decreased cardiac function has been generally reported, some studies in this review have specifically shown decreased left ventricular or left anterior descending coronary artery (LAD) function or perfusion after radiation.

A review of over 1600 patients with 16 years of follow-up found that left-sided breast cancer patients treated with radiation had a $38 \%$ increase in cardiovascular disease compared to right-sided cancer patients, though the rates of cardiovascular disease did not correlate with volume of heart irradiated (7). Recently, another review of 2168 women who underwent radiotherapy for breast cancer in Sweden and Denmark found that the average mean heart dose was 4.9 Gy and that there was a significant linear correlation between mean heart dose and rate of major coronary events, with an increase of $7.4 \%$ per Gy (8). Another study estimated the risk of cardiotoxicity to increase $4 \%$ per Gy mean heart dose (9).

It should be remembered that for patients with long follow-up, the treatment techniques used may be relatively outdated compared to those used today, and therefore, their reported cardiac doses may not represent typical doses today. In addition, for such patients, 3D dose and image data, which are routinely available today, were generally not available in many older studies, requiring more uncertain methods of estimating cardiac dose. While rates of cardiotoxicity are improving, and methods of delivering and quantifying dose of radiation to the heart have become more sophisticated, reducing potential for any cardiotoxicity remains one of the primary aims of improving adjuvant radiation techniques for patients with left-sided cancers.

This paper will focus on treatment of patients treated with radiation after breast-conserving surgery. Treatment fields, angles, and other radiotherapy techniques may be different for postmastectomy patients compared to patients with intact breasts. It is beyond the scope of this paper to attempt to discuss all aspects of plan evaluation for the studies discussed, such as planning target volume coverage, dose homogeneity, and dose to other organs. This review will focus solely on techniques to decrease radiation to the heart for women receiving radiation to the left breast.

\section{MATERIALS AND METHODS}

A Pubmed literature search was performed on March 5, 2014 to review any papers discussing breast cancer heart dosimetry. Articles were excluded if they reviewed non-breast cancer data, post-mastectomy radiation, exclusively evaluated patients with pectus excavatum, bilateral breast irradiation, or did not have heart 
dosimetric data. Articles were reviewed specifically for data from patients treated to the left breast. For this review, all studies are assumed to deliver whole breast irradiation unless partial breast treatment is stated.

\section{RESULTS}

\section{SUPINE 3D}

Traditionally, breast cancer has been treated in the supine position with arms above the head with two opposed tangent photon fields. The earliest data on cardiac toxicity originated from the Stockholm Breast Cancer trial, which treated patients to 45 Gy at $1.8 \mathrm{~Gy}$ per fraction, and found a 15 -year excess cardiac mortality of $6.8 \%$ attributed to the radiation (10). A review of patients treated in that trial estimated the mean volume of heart treated to the $50 \%$ isodose $(22.5 \mathrm{~Gy})$ to be $25 \%$ (11). One of the first trials to show an alternative approach to reduce heart dose was a review of the plans of 100 women with left-sided T1N0MO breast cancer status post-lumpectomy treated with three-dimensional conformal radiation therapy (3DCRT) planning to $50 \mathrm{~Gy}$ at $2 \mathrm{~Gy}$ per fraction, which reviewed the dose to the heart for these patients and found the volume treated to 50\% isodose to be 5.7\% (approximately $33 \mathrm{cc}$ ) (12). This significant reduction of heart dose led to the widespread adoption of 3D conformal planning for breast cancer. Some have shown that simply using 3DCRT to account for individual organ location, by putting a limit of $1 \mathrm{~cm}$ of heart in the tangent field, would cause at most a 1 per thousand patient risk of cardiac mortality (13). Several other studies have also shown reductions in planned heart dose with $3 \mathrm{D}$ conformal compared to two-dimensional planning $(14,15)$. However, one study showed no difference in mean heart dose, V20, or V5 heart dose comparing 2D, standard 3DCRT, and field-in-field (FiF) techniques (16).

Since the adoption of 3DCRT, many techniques have been attempted to further reduce cardiac radiation dose. A large study involving 217 left-sided breast cancer patients evaluated 3DCRT vs multi-segmented conformal radiation therapy and found no difference in mean heart dose (17). Another study confirmed this finding (18). A study evaluating tangential single wedge, double wedge, and FiF techniques found no significant differences in cardiac dose (19). A single study evaluating treating women with large breasts in the left lateral decubitus position was able to achieve a mean heart dose of 1.35 Gy for left-sided cancers (20). Using FiF planning can produce lower heart mean dose, V10, and V20 compared to standard 3DCRT plans (21). One study found that treating patients with their bra on decreased V5 to the heart from 9.8 to $2.7 \%$ (22). Hypofractionated whole breast regimens are becoming more common and have been shown to have equal slightly improved 2 Gy dose equivalent doses to the heart $(23,24)$.

\section{PRONE}

The largest and most current experience with prone breast treatment includes 200 women with left-sided breast cancer and has shown a significant decrease in in-field heart volumes compared to supine tangent plans with a mean reduction of $7.5 \mathrm{~cm}^{3}$, which corresponded to a $85.7 \%$ reduction in in-field heart volume (25). However, there was no benefit for women with smaller breasts (less than $750 \mathrm{~cm}^{3}$ ), and $15 \%$ of women overall had decrease in in-field heart volume when planned in the supine position. The second largest study comparing supine and prone planning, comparing whole breast and partial breast plans, found that prone positioning decreased cardiac doses for large breasted women but increased cardiac doses for women with smaller breast volume (26), a finding that has also been concluded in other studies $(27,28)$. One study found improvement in heart doses with prone positioning, but at the cost of a $50 \%$ reduction in coverage of the axillary nodes (29). Some smaller series have found no difference between supine and prone heart doses (29-31). Figure 2 provides examples of prone breast and an external beam accelerated partial breast irradiation (APBI) plans with corresponding isodose lines.

\section{INTENSITY-MODULATED RADIATION THERAPY}

As has been shown in many sites treated with intensity-modulated radiation therapy (IMRT), left-sided breast cancer patients treated with IMRT limits high dose to the heart without limiting low doses (32-35). Different techniques, including forward-planned IMRT, inverse-planned IMRT, and modulated arc therapies have been studied. A study of multiple partial arc volume-modulated arc therapy had a mean V25 to the heart of $2.52 \%$ of the heart volume, while having a mean total dose of $7.61 \mathrm{~Gy}$ (36). IMRT incorporating a simultaneous boost, even with respiratory gating, showed a mean heart dose of 22.98 Gy but reduced treatment duration by 6 fractions (37). Whether standard sequential boost or IMRT concomitant boost was used did not significantly affect heart dose (38). Forward-planned IMRT has been shown in one study to significantly reduce mean heart dose compared to inverse IMRT and arc radiotherapy (5.46 vs 15.48 vs 12.73 Gy) (39).

Many studies comparing IMRT to 3DCRT have shown decreased heart mean, V25, and V30 with IMRT compared to standard tangent fields (40-47), however, with no improvement over tangents with FiF (48). Other studies have failed to show a significant difference in most heart constraints for IMRT over 3DCRT (49). The largest study comparing 3DCRT vs IMRT, comparing 201 forward-planned IMRT cases to 131 3DCRT plans, stratified by breast size and use of supraclavicular nodal irradiation, found a non-significant trend toward reduced heart constraints with IMRT (50).

\section{TECHNOLOGICAL SOLUTIONS}

Breath hold, accomplished by having the patient take and hold a deep inspiration during CT simulation and during treatment each day, has been shown to significantly reduce heart dose. Several studies have shown that deep inspiration breath hold (DIBH) compared to free breathing (FB) reduced mean heart dose and several other dose constraints to the heart by $50 \%$, with mean heart doses around 2-3 Gy (51-55). A comparison of thoracic anatomy and radiation isodose lines with FB and DIBH can be seen in Figure 1, which demonstrates how the breath hold can change thoracic anatomy to potentially reduce cardiac dose received of radiation. A selective approach to using DIBH was used in one study, which evaluated 53 left breast patients and evaluated all patients with standard tangent field plans. Any patients with greater than $10 \mathrm{~cm}^{3}$ of heart receiving $50 \%$ of the prescription dose were selected for DIBH IMRT, and these DIBH IMRT cases had significantly reduced whole heart and LAD doses (56). One study combined DIBH with IMRT and significantly reduced heart 

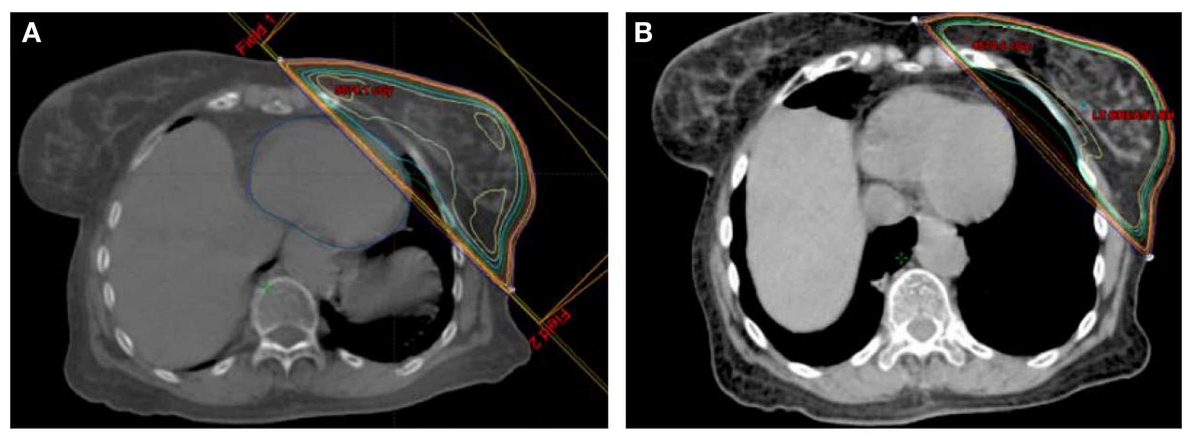

FIGURE 1 | Example of (A) free breathing and (B) deep inspiration breath hold plans for a single patient.
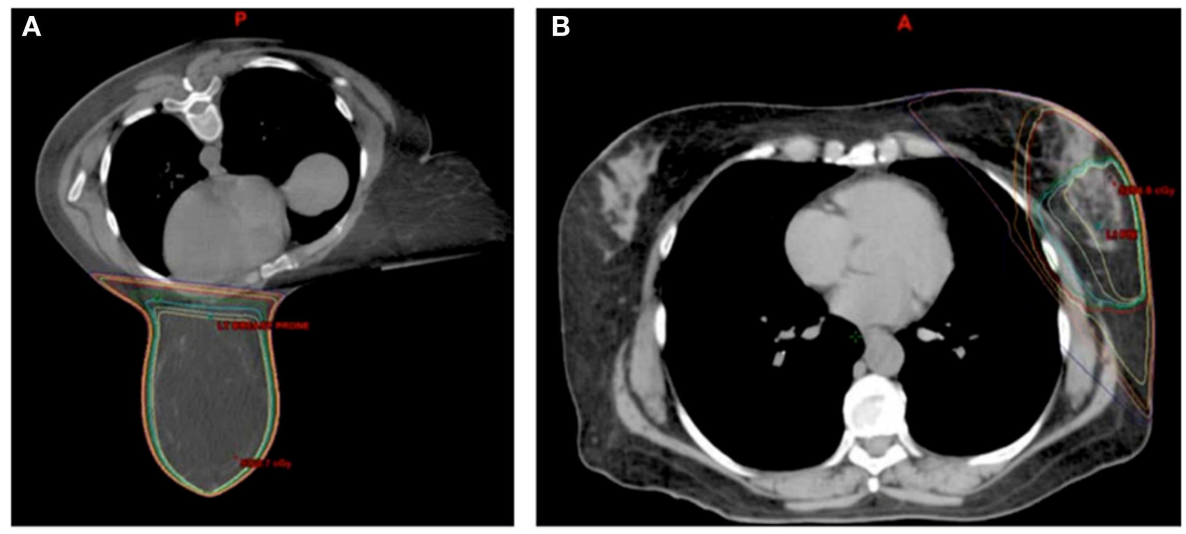

FIGURE 2 | Examples of (A) prone breast and (B) external beam APBI plans

V30 in two-thirds of the patients and was able to avoid any heart irradiation in $22 \%$ of cases (57). Another study, using cardiac MRI, similarly found that breath hold could displace the heart entirely out of the radiation field in $21 \%$ of patients (58).

One consideration of breath hold techniques is inter-fraction reproducibility of patient geometry and anatomy. When the breath hold is voluntary, respiratory coaching is required to ensure consistency. Two studies have shown good inter-fraction reproducibility with DIBH $(53,59)$. Monitoring technology such as magnetic sensors or real-time surface imaging can be used to verify and improve voluntary breath hold reproducibility $(59,60)$. Several studies rely on technology sometimes referred to as active breathing control, in which a patient breathes through a device that monitors breathing air volumes and automatically holds the patient's breath at prespecified volumes for a defined period of time (55, 57, 61-64). Some studies have explored the use of gating rather than breath hold to address intra-fraction respiratory motion $(60,65)$. Even with respiratory motion management such as breath hold, cardiac motion may still be an issue. Under breath hold conditions, one study showed that the LAD can show substantial displacement due to cardiac contraction (66). Another study used fluoroscopy to show potentially significant cardiac motion that was not evident using 4DCT techniques (67).
Changing the radiation particle from photons to protons and using MRI-linacs for photon treatment delivery are two newer approaches to improving treatment delivery. Proton radiotherapy is not commonly used for the breast; however, one study projected that a reduced risk of cardiac mortality might be achieved, based on planned cardiac doses, for proton and IMRT plans compared to 3DCRT (68). A study of breast radiotherapy using integrated MRI-linacs found no difference in heart D2cc or V25 for whole breast tangential and 7-field IMRT APBI plans (69). One potential application for future MRI-linacs is the appropriate application of a reversible transverse magnetic field, which in simulation resulted in a $26.0 \%$ mean heart dose reduction $(70)$.

\section{APBI}

Accelerated partial breast irradiation is a newer technique in women with low risk of recurrence for breast cancer to treat only the lumpectomy cavity with a small margin, rather than the whole breast and regional lymph nodes. Only women at least 60 years old with T1, node negative, estrogen receptor positive, unifocal or unicentric breast cancers with no lymphovascular invasion and negative margins are fully "suitable" for APBI, with a select group also considered "cautionary," per the American Society for Radiation Oncology (71). More recently, APBI guidelines were also 
created by the American Brachytherapy Society with slightly different criteria for "suitable" patients, such as slightly older age and no DCIS allowed (72). However, these guidelines are created by consensus panels for patients off protocol, rather than by randomized trials with set selection criteria. While APBI is only available for a select group of breast cancer patients, it is often able to significantly reduce dose to nearby structures including the heart.

A few studies have compared whole breast irradiation to ABPI. A study evaluating APBI using IMRT compared to whole breast using FiF planning (using radiobiologically adjusted results to account for the different fractionations) found that the APBI plan reduced the heart mean from 3.17 to $0.80 \mathrm{~Gy}(p=0.002)$ using APBI and reduced V5 from 8.75 to $4.94 \%(p=0.041)(73)$. Another review of patients being treated on NSABP-B39 for external beam APBI compared to plans for whole breast irradiation has significantly improved V2.5, V5, and V10 for lateral lumpectomy cavities but not for medial cavities, though V20 was improved with APBI regardless of lumpectomy location (74). Mammosite brachytherapy APBI compared to whole breast irradiation has been shown to significantly reduce maximum heart dose and V5, but not mean heart dose or V10 in one study (75), but single-source APBI brachytherapy did show an improvement in mean heart dose over whole breast from 2.52 to 1.65 Gy in another study (76).

Accelerated partial breast irradiation can be delivered via external beam radiation or via brachytherapy catheter(s) placed in the lumpectomy cavity. Studies of brachytherapy APBI have shown mean heart dose between 1.65 and 2.45 Gy and mean V5 between 1 and $59.2 \%$ (77-80). One study achieved a mean maximum heart doses around $2.2 \mathrm{~Gy}$ in both Mammosite and Clearpath brachytherapy catheters, though patients in this study have lesions closer to skin than chest wall (81). External beam studies have shown mean heart doses of 1.2 Gy and V5 of $1 \%(82,83)$. RTOG 0413 showed external partial breast irradiation with a mean V5 value at $1.1 \%$ for left-sided patients (84).

Accelerated partial breast irradiation with protons has been shown to be very effective at limiting heart dose with one study showing no dose greater than 3 Gy to the heart (85). One study evaluating volumetric-modulated arc radiotherapy (VMAT) was able to achieve an APBI plan with a mean heart dose of $0.72 \mathrm{~Gy}$, which was further reduced to $0.34 \mathrm{~Gy}$ (a 53\% reduction) when VMAT was combined with dynamic couch rotation to account for respiratory motion (86). When evaluating IMRT, VMAT, and continuous arc rotation of the couch APBI plans separately, compared to a 3DCRT APBI plan, the IMRT and continuous arc plans were able to significantly reduce the mean heart V5 from 3 to $1.1 \%$ and $1.7 \%$, respectively (87). Another study found that for pendulous breasts treated prone with IMRT APBI combined with dynamic couch motion could produce a plan that would deliver less than $0.1 \%$ of the prescribed dose to the heart (88).

\section{INTERNAL MAMMARY NODE AND BOOST CARDIAC CONTRIBUTION}

Slight variations in dose exist though most studies are close to a biologic equivalent dose (at 2 Gy per fraction) of $50 \mathrm{~Gy}$, though a significant variation in the implementation and dose of a boost to the surgical bed exist between studies. Another difficulty in evaluating cardiac dose is variability in treatment volume. Variability in coverage of internal mammary nodes (IMN), axillary, or supraclavicular nodes exists between studies. Adding axillary nodal or IMN coverage to tangent fields has been shown to increase the Dmax of the heart by $7-10 \%$ (89). Adding IMN coverage to whole breast irradiation increases the volume of heart irradiated by $13.8 \%$ for left breast cancers (90). When comparing plans with IMN in the treatment field, one study found no difference between wide-field, oblique photon-electron, and perpendicular photonelectron techniques (91), while another found decreased mean heart dose, V10, and V20 with wide tangents compared to plans using a separate IMN field (92).

The use and dose of a boost to the lumpectomy cavity is not standardized between studies, nor among practitioners, which contributes to the difficulty in comparing studies. The added mean heart dose of a $10 \mathrm{~Gy}$ boost in four fractions is $0.33 \mathrm{~Gy}$ for electron boost and $0.73 \mathrm{~Gy}$ for a photon boost via VMAT (93). Other studies have found decreased cardiac doses for proton and photon compared to electron boosts (94), and comparable V20 for Mammosite brachytherapy boost compared to electron boost (95).

\section{DISCUSSION}

One of the difficulties in comparing studies in radiation cardiac toxicity is the variable reported parameters to evaluate potential toxicity. For example, as mentioned previously, early studies evaluated the volume receiving $50 \%$ of the prescription dose (10-12). Another study reviewed SPECT perfusion scans in 20 women 6 months after breast radiation and found minimal decrease in perfusion if RT dose was kept less than $10 \mathrm{~Gy}$ and a $20 \%$ perfusion reduction if greater than $40 \mathrm{~Gy}$ (96), suggesting V10 and V40 as potential targets for plan evaluation. Strain rate imaging has also been used to evaluate cardiac damage from radiation and has shown that radiation of left breast patients led to a significant $2 \%$ reduction in left ventricle strain after radiation, particularly observed in regions of the heart exposed to 3 Gy or more (97), which was observed immediately after radiation and persistent when evaluated 14 months after radiation (98). Cardiac biomarkers have also been evaluated following breast irradiation, and while there was a significant increase in mean values of troponin I and Brain Natriuretic Peptide (from 0.007 to $0.014 \mathrm{ng} / \mathrm{mL}$ and 123 to $159 \mathrm{pg} / \mathrm{mL}$, respectively), the increase was not above normal reference values (99). A study of 681 breast cancer patients treated in Denmark who did not develop ischemic heart disease found that left-sided breast cancer patients had a mean heart dose of $6 \mathrm{~Gy}$, despite receiving coverage of IMN and supraclavicular fields (100). Mean heart dose is also used as a common reference dose constraint given reports of clinical outcomes in studies using this parameter (8). Table 1 provides a comparison of many studies that included mean heart dose data; however, caution should be used in comparing studies, as many studies included low numbers of patients, and extent of breast and nodal tissue covered differs from one study to another. Studies have failed to consistently show that LAD dose is independently predictive of cardiotoxicity more than whole heart measures and more reproducible from one physician to another. Therefore, whole heart dose remains a standard measure at present. However, further data are needed to more rigorously establish standards for dosimetric cardiac constraints.

Another challenge is defining the volume used to calculate these dose constraints. Slight variations in heart contours can exist from 
Table 1 | Summary of studies evaluating mean heart dose.

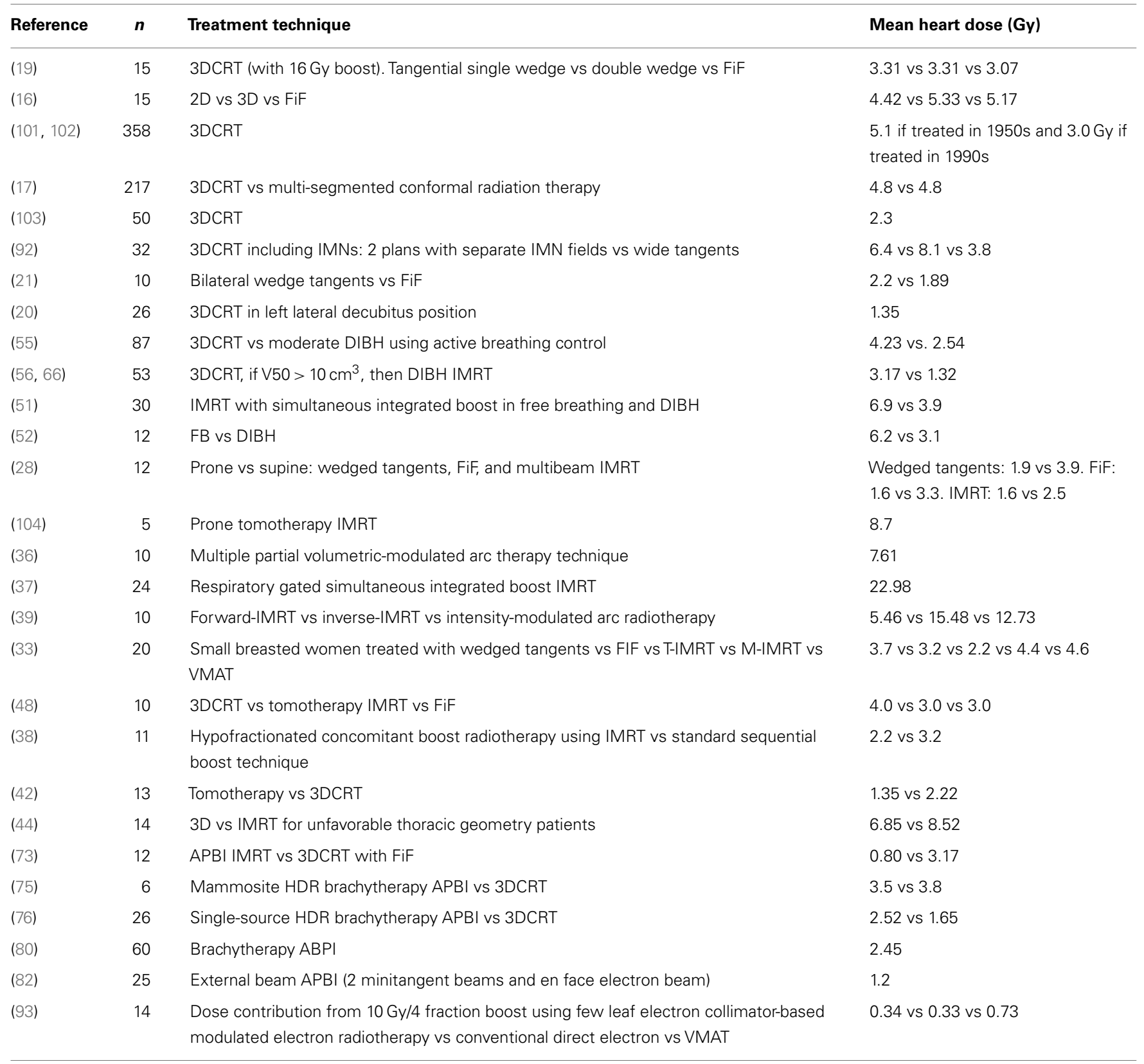

n: number of left-breast women in study (total number if left breast not specified); 3DCRT: three-dimensional conformal radiation therapy; FiF: field-in-field; IMN: internal mammary nodes; DIBH: deep inspiration breath hold; IMRT: intensity-modulated radiation therapy; FB: free breathing; APBI: accelerated partial breast irradiation; FB: free breathing; HDR: high dose rate; VMAT: volumetric-modulated arc therapy.

one radiation oncologist to another. Also, some have questioned whether it may be valuable to contour the LAD or other coronary vessels individually and whether to include the pericardium. For this reason, a heart atlas for CT contouring, developed jointly by cardiology, cardiac radiology, and radiation oncology, to delineate whole heart and separate coronary vessels, has been shown to improve accuracy of cardiac contours, and more consistent mean heart dose reporting, in a tested group of radiation oncologists (105). While this atlas was verified in a group, it is not used by all radiation oncologists and has not been used for contouring in other studies evaluating heart data, because such atlases are still relatively new. User contour variations, therefore, exist between studies. Some studies have suggested that the maximum heart distance in a treatment field, measured anterior to posterior, is relatively simple and correlates well with mean heart dose and other cardiac dose measurements $(101,106)$. However, another study showed that maximum heart distance only correlated with dose to the LAD when accounting for respiratory motion (107). A study of left-sided breast cancer patients where all plans had LAD, right, and circumflex coronary arteries contoured separately 
found that the mean whole heart dose was $2.3 \mathrm{~Gy}$, and $7.6 \mathrm{~Gy}$ to the LAD, and 2 Gy to the right and circumflex arteries (103). A recent study of supine standard tangential field plans found that for every $100 \mathrm{cGy}$ increase in mean heart dose the mean LAD dose increased by $4.82 \mathrm{~Gy}$, with direct correlations also seen with several other constraints, suggesting that LAD dose correlates very closely with whole heart parameters and LAD does not need to be contoured separately (108). However, another study using 3 field mono-isocentric partial wide tangents found that 11 of 24 patients had significant variability between mean heart dose and LAD dose (109). A study of 32 women on a randomized trial, treated with breast radiotherapy, evaluated the cardiac perfusion before and 1 year after radiation, and found no significant change in cardiac perfusion after radiation, even when assessing various cardiac subvolumes (110).

Variability in dose planned to dose received can exist. It can be difficult to determine the actual dose received. However, some studies provide insight into means of limiting the variability between these doses. It has been shown that patient setup errors of greater than $3 \mathrm{~mm}$ in the posterior direction result in significant increased dose to the heart $(111,112)$. The maximum anterior/posterior distance of heart in the treatment field has shown a strong linear correlation with mean heart dose (100). Even with image guidance, planning margins may be advisable as variability can exist between bone and/or surface anatomy and cardiac $(25,60,111)$.

The implementation of improving techniques for breast cancer radiotherapy can significantly reduce the heart radiation dose that breast cancer patients receive. A review of 358 women treated over several decades in Sweden found that even though a number of different treatment techniques were used, the overall mean heart dose to left-sided breast cancer patients was $5.1 \mathrm{~Gy}$ in the 1950 s compared to 3.0 Gy for women treated in the 1990s (102). However, it should be remembered that even clear dosimetric advantages in the treatment planning stage may not translate to improvements in clinical outcomes (63).

Radiation is not the only factor contributing to cardiac toxicity in breast cancer patients, as other aspects of their treatment can influence cardiac toxicity. For example, a large study involving doxorubicin and cyclophosphamide chemotherapy with radiation to either the right or left breast (with or without IMN coverage) found that the number of cycles of doxorubicin was a more significant factor in cardiac toxicity than the amount of heart in the radiation field (113). Therefore, all aspects of patient care must be accounted for to reduce cardiac toxicity.

The decision of which treatment planning technique for delivery of radiotherapy following breast-conserving surgery includes consideration of many factors about the patient. One important factor in that decision is radiation doses received to the heart, as decreasing radiation doses to the heart can potentially prevent unnecessary cardiotoxicity. Many different techniques are available, as discussed in this review, to significantly reduce radiation doses to the heart, thereby providing means to decrease cardiac toxicity risk for women undergoing such treatment.

Several techniques have been shown to improve cardiac doses over standard supine 3DCRT tangents. Prone positioning has been shown to improve cardiac doses for patients with large pendulous breaths, though not for smaller breasted patients. Breath hold can also significantly reduce heart dose by displacing the heart away from the chest wall. APBI can be effective in reducing cardiac radiation doses though this is dependent on the location of the tumor/lumpectomy cavity and is only suitable for a select portion of breast cancer patients. Use of seroma boost and IMN irradiation has been shown to increase cardiac dose, though the cardiac risk needs to be weighed against the risk of recurrence.

\section{REFERENCES}

1. What are the Key Statistics about Breast Cancer? (2014). Available from: www. cancer.org/cancer/breastcancer/detailedguide/breast-cancer-key-statistics

2. Fisher B, Anderson S, Bryant J, Margolese RG, Deutsch M, Fisher ER, et al. Twenty-year follow-up of a randomized trial comparing total mastectomy, lumpectomy, and lumpectomy plus irradiation for the treatment of invasive breast cancer. New Engl J Med (2002) 347(16):1233-41. doi:10.1056/ NEJMoa022152

3. Wehr M, Rosskopf BG, Pittner PM, Schwenk D, Prignitz R. Heart function during postoperative high-voltage therapy in female patients with left-sided breast cancer. Klin Wochenschr (1982) 60(24):1505-7. doi:10.1007/BF01716103

4. Gagliardi G, Lax I, Soderstrom S, Gyenes G, Rutqvist LE. Prediction of excess risk of long-term cardiac mortality after radiotherapy of stage I breast cancer. Radiother Oncol (1998) 46(1):63-71. doi:10.1016/S0167-8140(97)00167-9

5. McGale P, Darby SC, Hall P, Adolfsson J, Bengtsson N, Bennet AM, et al. Incidence of heart disease in 35,000 women treated with radiotherapy for breast cancer in Denmark and Sweden. Radiother Oncol (2011) 100(2):167-75. doi:10.1016/j.radonc.2011.06.016

6. Hooning MJ, Botma A, Aleman BM, Baaijens MH, Bartelink H, Klijn JG, et al. Long-term risk of cardiovascular disease in 10-year survivors of breast cancer. J Natl Cancer Inst (2007) 99(5):365-75. doi:10.1093/jnci/djk064

7. Borger JH, Hooning MJ, Boersma LJ, Snijders-Keilholz A, Aleman BM, Lintzen $\mathrm{E}$, et al. Cardiotoxic effects of tangential breast irradiation in early breast cancer patients: the role of irradiated heart volume. Int J Radiat Oncol Biol Phys (2007) 69(4):1131-8. doi:10.1016/j.ijrobp.2007.04.042

8. Darby SC, Ewertz M, McGale P, Bennet AM, Blom-Goldman U, Bronnum D, et al. Risk of ischemic heart disease in women after radiotherapy for breast cancer. N Engl J Med (2013) 368(11):987-98. doi:10.1056/NEJMoa1209825

9. Mege A, Zioueche A, Pourel N, Chauvet B. [Radiation-related heart toxicity]. Cancer Radiother (2011) 15(6-7):495-503. doi:10.1016/j.canrad.2011.06.003

10. Rutqvist LE, Lax I, Fornander T, Johansson H. Cardiovascular mortality in a randomized trial of adjuvant radiation therapy versus surgery alone in primary breast cancer. Int J Radiat Oncol Biol Phys (1992) 22(5):887-96.

11. Gagliardi G, Lax I, Ottolenghi A, Rutqvist LE. Long-term cardiac mortality after radiotherapy of breast cancer - application of the relative seriality model. Br J Radiol (1996) 69(825):839-46.

12. Gyenes G, Gagliardi G, Lax I, Fornander T, Rutqvist LE. Evaluation of irradiated heart volumes in stage I breast cancer patients treated with postoperative adjuvant radiotherapy. J Clin Oncol (1997) 15(4):1348-53.

13. Muren LP, Maurstad G, Hafslund R, Anker G, Dahl O. Cardiac and pulmonary doses and complication probabilities in standard and conformal tangential irradiation in conservative management of breast cancer. Radiother Oncol (2002) 62(2):173-83. doi:10.1016/S0167-8140(01)00468-6

14. Erven K, Petillion S, Weltens C, Van den Heuvel F, Defraene G, Van Limbergen $\mathrm{E}$, et al. Conformal locoregional breast irradiation with an oblique parasternal photon field technique. Med Dosim (2011) 36(1):28-34. doi:10.1016/j.meddos. 2009.10.006

15. Vivekanandan S, Mhlanga J, Launders D, Przeslak A, Morgan DA. Beam angle manipulation to reduce cardiac dose during breast radiotherapy. Br J Radiol (2012) 85(1011):265-71. doi:10.1259/bjr/58636261

16. Gursel B, Meydan D, Ozbek N, Ofluoglu T. Dosimetric comparison of three different external beam whole breast irradiation techniques. Adv Ther (2011) 28(12):1114-25. doi:10.1007/s12325-011-0078-1

17. Gulyban A, Kovacs P, Sebestyen Z, Farkas R, Csere T, Karacsonyi G, et al. Multisegmented tangential breast fields: a rational way to treat breast cancer. Strahlenther Onkol (2008) 184(5):262-9. doi:10.1007/s00066-008-1770-1

18. Ludwig V, Schwab F, Guckenberger M, Krieger T, Flentje M. Comparison of wedge versus segmented techniques in whole breast irradiation: effects 
on dose exposure outside the treatment volume. Strahlenther Onkol (2008) 184(6):307-12. doi:10.1007/s00066-008-1793-7

19. Onal C, Sonmez A, Arslan G, Oymak E, Kotek A, Efe E, et al. Dosimetric comparison of the field-in-field technique and tangential wedged beams for breast irradiation. Jpn J Radiol (2012) 30(3):218-26. doi:10.1007/s11604-0110034-7

20. Kirova YM, Hijal T, Campana F, Fournier-Bidoz N, Stilhart A, Dendale R, et al. Whole breast radiotherapy in the lateral decubitus position: a dosimetric and clinical solution to decrease the doses to the organs at risk (OAR). Radiother Oncol (2014) 110(3):477-81. doi:10.1016/j.radonc.2013.10.038

21. Ercan T, Igdem S, Alco G, Zengin F, Atilla S, Dincer M, et al. Dosimetric comparison of field in field intensity-modulated radiotherapy technique with conformal radiotherapy techniques in breast cancer. Jpn J Radiol (2010) 28(4):283-9. doi:10.1007/s11604-010-0423-3

22. Arenas M, Hernandez V, Farrus B, Muller K, Gascon M, Pardo A, et al. Do breast cups improve breast cancer dosimetry? A comparative study for patients with large or pendulous breasts. Acta Oncol (2014) 53(6):795-801. doi:10.3109/0284186X.2014.893062

23. Appelt AL, Vogelius IR, Bentzen SM. Modern hypofractionation schedules for tangential whole breast irradiation decrease the fraction size-corrected dose to the heart. Clin Oncol (2013) 25(3):147-52. doi:10.1016/j.clon.2012.07.012

24. Venables K, Miles EA, Deighton A, Aird EG, Hoskin PJ. Irradiation of the heart during tangential breast treatment: a study within the START trial. Br J Radiol (2004) 77(914):137-42. doi:10.1259/bjr/11764177

25. Formenti SC, DeWyngaert JK, Jozsef G, Goldberg JD. Prone vs supine positioning for breast cancer radiotherapy. JAMA (2012) 308(9):861-3. doi:10.1001/ 2012.jama.10759

26. Kirby AM, Evans PM, Donovan EM, Convery HM, Haviland JS, Yarnold JR. Prone versus supine positioning for whole and partial-breast radiotherapy: a comparison of non-target tissue dosimetry. Radiother Oncol (2010) 96(2):178-84. doi:10.1016/j.radonc.2010.05.014

27. Merchant TE, McCormick B, Yahalom J, Borgen P. The influence of older age on breast cancer treatment decisions and outcome. Int J Radiat Oncol Biol Phys (1996) 34(3):565-70. doi:10.1016/0360-3016(95)02167-1

28. Mulliez T, Speleers B, Madani I, De Gersem W, Veldeman L, De Neve W. Whole breast radiotherapy in prone and supine position: is there a place for multibeam IMRT? Radiat Oncol (2013) 8:151. doi:10.1186/1748-717X-8-151

29. Alonso-Basanta M, Ko J, Babcock M, Dewyngaert JK, Formenti SC. Coverage of axillary lymph nodes in supine vs. prone breast radiotherapy. Int J Radiat Oncol Biol Phys (2009) 73(3):745-51. doi:10.1016/j.ijrobp.2008.04.040

30. Griem KL, Fetherston P, Kuznetsova M, Foster GS, Shott S, Chu J. Threedimensional photon dosimetry: a comparison of treatment of the intact breast in the supine and prone position. Int J Radiat Oncol Biol Phys (2003) 57(3):891-9. doi:10.1016/S0360-3016(03)00723-5

31. Varga Z, Hideghety K, Mezo T, Nikolenyi A, Thurzo L, Kahan Z. Individual positioning: a comparative study of adjuvant breast radiotherapy in the prone versus supine position. Int J Radiat Oncol Biol Phys (2009) 75(1):94-100. doi:10.1016/j.ijrobp.2008.10.045

32. Cozzi L, Fogliata A, Nicolini G, Bernier J. Clinical experience in breast irradiation with intensity modulated photon beams. Acta Oncol (2005) 44(5):467-74. doi:10.1080/02841860510029879

33. Jin GH, Chen LX, Deng XW, Liu XW, Huang Y, Huang XB. A comparative dosimetric study for treating left-sided breast cancer for small breast size using five different radiotherapy techniques: conventional tangential field, filed-in-filed, tangential-IMRT, multi-beam IMRT and VMAT. Radiat Oncol (2013) 8:89. doi:10.1186/1748-717X-8-89

34. Liem X, Chira C, Fourquet A, Campana F, Peurien D, Fournier-Bidoz N, et al. [Preliminary results of whole breast helical tomotherapy with simultaneous integrated boost in the adjuvant treatment of breast cancer]. Cancer Radiother (2014) 18(1):15-22. doi:10.1016/j.canrad.2013.07.149

35. Zhang F, Zheng M. Dosimetric evaluation of conventional radiotherapy, 3-D conformal radiotherapy and direct machine parameter optimisation intensitymodulated radiotherapy for breast cancer after conservative surgery. $J$ Med Imaging Radiat Oncol (2011) 55(6):595-602. doi:10.1111/j.1754-9485.2011. 02313.x

36. Tsai PF, Lin SM, Lee SH, Yeh CY, Huang YT, Lee CC, et al. The feasibility study of using multiple partial volumetric-modulated arcs therapy in early stage left-sided breast cancer patients. J Appl Clin Med Phys (2012) 13(5):3806. doi:10.1120/jacmp.v13i5.3806
37. Majumdar D, Mohammed SS, Naseer MA, Jacob J, Mohan R, Ebenezer SB, et al. Respiratory gated simultaneous integrated boost-intensity modulated radiotherapy (SIB-IMRT) after breast conservative surgery for carcinoma of the breast: the Salmaniya medical complex experience. Gulf J Oncolog (2011) (10):53-9.

38. Teh AY, Walsh L, Purdie TG, Mosseri A, Xu W, Levin W, et al. Concomitant intensity modulated boost during whole breast hypofractionated radiotherapy - a feasibility and toxicity study. Radiother Oncol (2012) 102(1):89-95. doi:10.1016/j.radonc.2011.10.015

39. Yin Y, Chen J, Sun T, Ma C, Lu J, Liu T, et al. Dosimetric research on intensity-modulated arc radiotherapy planning for left breast cancer after breast-preservation surgery. Med Dosim (2012) 37(3):287-92. doi:10.1016/j. meddos.2011.11.001

40. Cavey ML, Bayouth JE, Endres EJ, Pena JM, Colman M, Hatch S. Dosimetric comparison of conventional and forward-planned intensity-modulated techniques for comprehensive locoregional irradiation of post-mastectomy left breast cancers. Med Dosim (2005) 30(2):107-16. doi:10.1016/j.meddos.2005. 02.002

41. Chui CS, Hong L, Hunt M, McCormick B. A simplified intensity modulated radiation therapy technique for the breast. Med Phys (2002) 29(4):522-9. doi:10.1118/1.1460875

42. Hijal T, Fournier-Bidoz N, Castro-Pena P, Kirova YM, Zefkili S, Bollet MA, et al. Simultaneous integrated boost in breast conserving treatment of breast cancer: a dosimetric comparison of helical tomotherapy and three-dimensional conformal radiotherapy. Radiother Oncol (2010) 94(3):300-6. doi:10.1016/j. radonc.2009.12.043

43. Li JS, Freedman GM, Price R, Wang L, Anderson P, Chen L, et al. Clinical implementation of intensity-modulated tangential beam irradiation for breast cancer. Med Phys (2004) 31(5):1023-31. doi:10.1118/1.1690195

44. Lohr F, El-Haddad M, Dobler B, Grau R, Wertz HJ, Kraus-Tiefenbacher U, et al. Potential effect of robust and simple IMRT approach for left-sided breast cancer on cardiac mortality. Int J Radiat Oncol Biol Phys (2009) 74(1):73-80. doi:10.1016/j.ijrobp.2008.07.018

45. Popescu CC, Olivotto IA, Beckham WA, Ansbacher W, Zavgorodni S, Shaffer R, et al. Volumetric modulated arc therapy improves dosimetry and reduces treatment time compared to conventional intensity-modulated radiotherapy for locoregional radiotherapy of left-sided breast cancer and internal mammary nodes. Int J Radiat Oncol Biol Phys (2010) 76(1):287-95. doi:10.1016/j.ijrobp.2009.05.038

46. Rongsriyam K, Rojpornpradit P, Lertbutsayanukul C, Sanghangthum T, Oonsiri S. Dosimetric study of inverse-planed intensity modulated, forward-planned intensity modulated and conventional tangential techniques in breast conserving radiotherapy. J Med Assoc Thai (2008) 91(10):1571-82.

47. Thilmann C, Sroka-Perez G, Krempien R, Hoess A, Wannenmacher M, Debus J. Inversely planned intensity modulated radiotherapy of the breast including the internal mammary chain: a plan comparison study. Technol Cancer Res Treat (2004) 3(1):69-75. doi:10.1177/153303460400300108

48. Borca VC, Franco P, Catuzzo P, Migliaccio F, Zenone F, Aimonetto S, et al. Does TomoDirect 3DCRT represent a suitable option for post-operative whole breast irradiation? A hypothesis-generating pilot study. Radiat Oncol (2012) 7:211. doi:10.1186/1748-717X-7-211

49. Ahmed RS, De Los Santos JF, Fiveash JB, Keene KS, Popple RA. An IMRT technique to increase therapeutic ratio of breast irradiation in patients with early-stage left breast cancer: limiting second malignancies. Med Dosim (2008) 33(1):71-7. doi:10.1016/j.meddos.2007.10.001

50. Morganti AG, Cilla S, de Gaetano A, Panunzi S, Digesu C, Macchia G, et al. Forward planned intensity modulated radiotherapy (IMRT) for whole breast postoperative radiotherapy. Is it useful? When? J Appl Clin Med Phys (2011) 12(2):3451.

51. Hayden AJ, Rains M, Tiver K. Deep inspiration breath hold technique reduces heart dose from radiotherapy for left-sided breast cancer. J Med Imaging Radiat Oncol (2012) 56(4):464-72. doi:10.1111/j.1754-9485.2012.02405.x

52. Hjelstuen MH, Mjaaland I, Vikstrom J, Dybvik KI. Radiation during deep inspiration allows loco-regional treatment of left breast and axillary-, supraclavicular- and internal mammary lymph nodes without compromising target coverage or dose restrictions to organs at risk. Acta Oncol (2012) 51(3):333-44. doi:10.3109/0284186X.2011.618510

53. McIntosh A, Shoushtari AN, Benedict SH, Read PW, Wijesooriya K. Quantifying the reproducibility of heart position during treatment and corresponding 
delivered heart dose in voluntary deep inhalation breath hold for left breast cancer patients treated with external beam radiotherapy. Int J Radiat Oncol Biol Phys (2011) 81(4):e569-76. doi:10.1016/j.ijrobp.2011.01.044

54. Stranzl H, Zurl B, Langsenlehner T, Kapp KS. Wide tangential fields including the internal mammary lymph nodes in patients with left-sided breast cancer. Influence of respiratory-controlled radiotherapy (4D-CT) on cardiac exposure. Strahlenther Onkol (2009) 185(3):155-60. doi:10.1007/s00066-009$1939-2$

55. Swanson T, Grills IS, Ye H, Entwistle A, Teahan M, Letts N, et al. Six-year experience routinely using moderate deep inspiration breath-hold for the reduction of cardiac dose in left-sided breast irradiation for patients with earlystage or locally advanced breast cancer. Am J Clin Oncol (2013) 36(1):24-30. doi:10.1097/COC.0b013e31823fe481

56. Wang W, Purdie TG, Rahman M, Marshall A, Liu FF, Fyles A. Rapid automated treatment planning process to select breast cancer patients for active breathing control to achieve cardiac dose reduction. Int J Radiat Oncol Biol Phys (2012) 82(1):386-93. doi:10.1016/j.ijrobp.2010.09.026

57. Remouchamps VM, Letts N, Yan D, Vicini FA, Moreau M, Zielinski JA, et al. Three-dimensional evaluation of intra- and interfraction immobilization of lung and chest wall using active breathing control: a reproducibility study with breast cancer patients. Int J Radiat Oncol Biol Phys (2003) 57(4):968-78. doi:10.1016/S0360-3016(03)00710-7

58. Chen MH, Cash EP, Danias PG, Kissinger KV, Bornstein BA, Rhodes LM, et al. Respiratory maneuvers decrease irradiated cardiac volume in patients with left-sided breast cancer. J Cardiovasc Magn Reson (2002) 4(2):265-71. doi:10.1081/JCMR-120003952

59. Remouchamps VM, Huyskens DP, Mertens I, Destine M, Van Esch A, Salamon E, et al. The use of magnetic sensors to monitor moderate deep inspiration breath hold during breast irradiation with dynamic MLC compensators. Radiother Oncol (2007) 82(3):341-8. doi:10.1016/j.radonc.2006.11.015

60. Alderliesten T, Betgen A, Elkhuizen PH, van Vliet-Vroegindeweij C, Remeijer P. Estimation of heart-position variability in 3D-surface-image-guided deepinspiration breath-hold radiation therapy for left-sided breast cancer. Radiother Oncol (2013) 109(3):442-7. doi:10.1016/j.radonc.2013.09.017

61. George R, Keall PJ, Kini VR, Vedam SS, Siebers JV, Wu Q, et al. Quantifying the effect of intrafraction motion during breast IMRT planning and dose delivery. Med Phys (2003) 30(4):552-62. doi:10.1118/1.1543151

62. Bartlett FR, Colgan RM, Carr K, Donovan EM, McNair HA, Locke I, et al. The UK HeartSpare study: randomised evaluation of voluntary deep-inspiratory breath-hold in women undergoing breast radiotherapy. Radiother Oncol (2013) 108(2):242-7. doi:10.1016/j.radonc.2013.04.021

63. Zellars R, Bravo PE, Tryggestad E, Hopfer K, Myers L, Tahari A, et al. SPECT analysis of cardiac perfusion changes after whole-breast/chest wall radiation therapy with or without active breathing coordinator: results of a randomized phase 3 trial. Int J Radiat Oncol Biol Phys (2014) 88(4):778-85. doi:10.1016/j.ijrobp.2013.12.035

64. Jagsi R, Moran JM, Kessler ML, Marsh RB, Balter JM, Pierce LJ. Respiratory motion of the heart and positional reproducibility under active breathing control. Int J Radiat Oncol Biol Phys (2007) 68(1):253-8. doi:10.1016/j.ijrobp.2006. 12.058

65. Korreman SS, Pedersen AN, Aarup LR, Nottrup TJ, Specht L, Nystrom H. Reduction of cardiac and pulmonary complication probabilities after breathing adapted radiotherapy for breast cancer. Int J Radiat Oncol Biol Phys (2006) 65(5):1375-80. doi:10.1016/j.ijrobp.2006.03.046

66. Wang X, Pan T, Pinnix C, Zhang SX, Salehpour M, Sun TL, et al. Cardiac motion during deep-inspiration breath-hold: implications for breast cancer radiotherapy. Int J Radiat Oncol Biol Phys (2012) 82(2):708-14. doi:10.1016/j. ijrobp.2011.01.035

67. Yue N, Goyal S, Park J, Jones S, Xu X, Khan A, et al. TH-C-WAB-07:optimization of heart block in the left-sided whole breast irradiation. Med Phys (2013) 40:537. doi:10.1118/1.4815764

68. Johansson J, Isacsson U, Lindman H, Montelius A, Glimelius B. Node-positive left-sided breast cancer patients after breast-conserving surgery: potential outcomes of radiotherapy modalities and techniques. Radiother Oncol (2002) 65(2):89-98. doi:10.1016/S0167-8140(02)00266-9

69. Van Heijst TC, den Hartogh MD, Lagendijk JJ, van den Bongard HJ, van Asselen B. MR-guided breast radiotherapy: feasibility and magnetic-field impact on skin dose. Phys Med Biol (2013) 58(17):5917-30. doi:10.1088/0031-9155/ $58 / 17 / 5917$
70. Esmaeeli AD, Mahdavi SR, Pouladian M, Monfared AS, Bagheri S. Improvement of dose distribution in breast radiotherapy using a reversible transverse magnetic field Linac-MR unit. Med Phys (2014) 41(1):011709. doi:10.1118/1. 4845175

71. Smith BD, Arthur DW, Buchholz TA, Haffty BG, Hahn CA, Hardenbergh PH, et al. Accelerated partial breast irradiation consensus statement from the American society for radiation oncology (ASTRO). Int J Radiat Oncol Biol Phys (2009) 74(4):987-1001. doi:10.1016/j.ijrobp.2009.02.031

72. Shah C, Vicini F, Wazer DE, Arthur D, Patel RR. The American brachytherapy society consensus statement for accelerated partial breast irradiation. Brachytherapy (2013) 12:267-77. doi:10.1016/j.brachy.2013.02.001

73. Wu S, He Z, Guo J, Li F, Lin Q, Guan X. Dosimetric comparison of normal structures associated with accelerated partial breast irradiation and whole breast irradiation delivered by intensity modulated radiotherapy for early breast cancer after breast conserving surgery. Clin Transl Oncol (2014) 16(1):69-76. doi:10.1007/s12094-013-1044-y

74. Gale AA, Jain AK, Vallow LA, Serago CF, Buskirk SJ, Heckman MG. Cardiac dose evaluation for 3-dimensional conformal partial breast irradiation compared with whole breast irradiation. J Appl Clin Med Phys (2009) 10(1):2868. doi:10.1120/jacmp.v10i1.2868

75. Stewart AJ, O'Farrell DA, Cormack RA, Hansen JL, Khan AJ, Mutyala S, et al. Dose volume histogram analysis of normal structures associated with accelerated partial breast irradiation delivered by high dose rate brachytherapy and comparison with whole breast external beam radiotherapy fields. Radiat Oncol (2008) 3:39. doi:10.1186/1748-717X-3-39

76. Garza R, Albuquerque K, Sethi A. Lung and cardiac tissue doses in left breast cancer patients treated with single-source breast brachytherapy compared to external beam tangent fields. Brachytherapy (2006) 5(4):235-8. doi:10.1016/j.brachy.2006.08.001

77. Dickler A, Kirk MC, Seif N, Griem K, Dowlatshahi K, Francescatti D, et al. A dosimetric comparison of MammoSite high-dose-rate brachytherapy and xoft axxent electronic brachytherapy. Brachytherapy (2007) 6(2):164-8. doi:10.1016/j.brachy.2007.01.005

78. Dickler A, Seif N, Kirk MC, Patel MB, Bernard D, Coon A, et al. A dosimetric comparison of MammoSite and clear path high-dose-rate breast brachytherapy devices. Brachytherapy (2009) 8(1):14-8. doi:10.1016/j.brachy.2008.07.006

79. Dooley WC, Wurzer JC, Megahy M, Schreiber G, Roy T, Proulx G, et al. Electronic brachytherapy as adjuvant therapy for early stage breast cancer: a retrospective analysis. Onco Targets Ther (2011) 4:13-20. doi:10.2147/OTT. S15297

80. Valakh V, Kim Y, Werts ED, Trombetta MG. A comprehensive analysis of cardiac dose in balloon-based high-dose-rate brachytherapy for left-sided breast cancer. Int J Radiat Oncol Biol Phys (2012) 82(5):1698-705. doi:10.1016/j.ijrobp. 2011.02.058

81. Beriwal S, Coon D, Kim H, Haley M, Patel R, Das R. Multicatheter hybrid breast brachytherapy: a potential alternative for patients with inadequate skin distance. Brachytherapy (2008) 7(4):301-4. doi:10.1016/j.brachy.2008.07.003

82. Bourgier C, Pichenot C, Verstraet R, Heymann S, Biron B, Balleyguier C, et al. [Accelerated partial breast irradiation: bifractionated 40Gy in one week. A French pilot phase II study]. Cancer Radiother (2010) 14(8):718-26. doi:10.1016/j.canrad.2010.05.006

83. Khan AJ, Kirk MC, Mehta PS, Seif NS, Griem KL, Bernard DA, et al. A dosimetric comparison of three-dimensional conformal, intensity-modulated radiation therapy, and MammoSite partial-breast irradiation. Brachytherapy (2006) 5(3):183-8. doi:10.1016/j.brachy.2006.06.001

84. Wen B, Hsu H, Formenti-Ujlaki GF, Lymberis S, Magnolfi C, Zhao X, et al. Prone accelerated partial breast irradiation after breast-conserving surgery: compliance to the dosimetry requirements of RTOG-0413. Int J Radiat Oncol Biol Phys (2012) 84(4):910-6. doi:10.1016/j.ijrobp.2012.01.055

85. Moon SH, Shin KH, Kim TH, Yoon M, Park S, Lee DH, et al. Dosimetric comparison of four different external beam partial breast irradiation techniques: three-dimensional conformal radiotherapy, intensity-modulated radiotherapy, helical tomotherapy, and proton beam therapy. Radiother Oncol (2009) 90(1):66-73. doi:10.1016/j.radonc.2008.09.027

86. Smyth G, Bamber JC, Evans PM, Bedford JL. Trajectory optimization for dynamic couch rotation during volumetric modulated arc radiotherapy. Phys Med Biol (2013) 58(22):8163-77. doi:10.1088/0031-9155/58/22/8163

87. Shaitelman SF, Kim LH, Yan D, Martinez AA, Vicini FA, Grills IS. Continuous arc rotation of the couch therapy for the delivery of accelerated partial breast 
irradiation: a treatment planning analysis. Int J Radiat Oncol Biol Phys (2011) 80(3):771-8. doi:10.1016/j.ijrobp.2010.03.004

88. Fahimian B, Yu V, Horst K, Xing L, Hristov D. Trajectory modulated prone breast irradiation: a LINAC-based technique combining intensity modulated delivery and motion of the couch. Radiother Oncol (2013) 109(3):475-81. doi:10.1016/j.radonc.2013.10.031

89. Lim TS, Petersen V, Zissiadis Y. CT planning for breast cancer. Australas Radiol (2007) 51(3):289-95. doi:10.1111/j.1440- 1673.2007.01732.x

90. Chargari C, Castadot P, Macdermed D, Vandekerkhove C, Bourgois N, Van Houtte $\mathrm{P}$, et al. Internal mammary lymph node irradiation contributes to heart dose in breast cancer. Med Dosim (2010) 35(3):163-8. doi:10.1016/j.meddos. 2009.05.002

91. Dogan MH, Zincircioglu SB, Zorlu F. Comparison of various radiation therapy techniques in breast cancer where target volume includes mammaria interna region. Med Dosim (2009) 34(1):42-50. doi:10.1016/j.meddos.2007. 11.003

92. Sautter-Bihl ML, Hültenschmidt B, Melcher U, Ulmer HU. Radiotherapy of internal mammary lymph nodes in breast cancer. Principle considerations on the basis of dosimetric data. Strahlenther Onkol (2002) 178(1):18-24. doi:10.1007/s00066-002-0848-4

93. Alexander A, Soisson E, Hijal T, Sarfehnia A, Seuntjens J. Comparison of modulated electron radiotherapy to conventional electron boost irradiation and volumetric modulated photon arc therapy for treatment of tumour bed boost in breast cancer. Radiother Oncol (2011) 100(2):253-8. doi:10.1016/j.radonc. 2011.05.081

94. Toscas JI, Linero D, Rubio I, Hidalgo A, Arnalte R, Escude L, et al. Boosting the tumor bed from deep-seated tumors in early-stage breast cancer: a planning study between electron, photon, and proton beams. Radiother Oncol (2010) 96(2):192-8. doi:10.1016/j.radonc.2010.05.007

95. Shah AP, Strauss JB, Kirk MC, Chen SS, Dickler A. A dosimetric analysis comparing electron beam with the MammoSite brachytherapy applicator for intact breast boost. Phys Med (2010) 26(2):80-7. doi:10.1016/j.ejmp.2009. 08.004

96. Hardenbergh PH, Munley MT, Bentel GC, Kedem R, Borges-Neto S, Hollis D, et al. Cardiac perfusion changes in patients treated for breast cancer with radiation therapy and doxorubicin: preliminary results. Int $J$ Radiat Oncol Biol Phys (2001) 49(4):1023-8. doi:10.1016/S0360-3016(00) 01531-5

97. Erven K, Jurcut R, Weltens C, Giusca S, Ector J, Wildiers H, et al. Acute radiation effects on cardiac function detected by strain rate imaging in breast cancer patients. Int J Radiat Oncol Biol Phys (2011) 79(5):1444-51. doi:10.1016/j.ijrobp.2010.01.004

98. Erven K, Weltens C, Nackaerts K, Fieuws S, Decramer M, Lievens Y. Changes in pulmonary function up to 10 years after locoregional breast irradiation. Int J Radiat Oncol Biol Phys (2012) 82(2):701-7. doi:10.1016/j.ijrobp. 2010.12.058

99. Nellessen U, Zingel M, Hecker H, Bahnsen J, Borschke D. Effects of radiation therapy on myocardial cell integrity and pump function: which role for cardiac biomarkers? Chemotherapy (2010) 56(2):147-52. doi:10.1159/ 000313528

100. Taylor CW, Bronnum D, Darby SC, Gagliardi G, Hall P, Jensen MB, et al. Cardiac dose estimates from Danish and Swedish breast cancer radiotherapy during 1977-2001. Radiother Oncol (2011)100(2):176-83. doi:10.1016/j.radonc. 2011.01.020

101. Taylor CW, McGale P, Povall JM, Thomas E, Kumar S, Dodwell D, et al. Estimating cardiac exposure from breast cancer radiotherapy in clinical practice. Int J Radiat Oncol Biol Phys (2009) 73(4):1061-8. doi:10.1016/j.jirobp. 2008.05.066

102. Taylor CW, Nisbet A, McGale P, Goldman U, Darby SC, Hall P, et al. Cardiac doses from Swedish breast cancer radiotherapy since the 1950s. Radiother Oncol (2009) 90(1):127-35. doi:10.1016/j.radonc.2008.09.029
103. Taylor CW, Povall JM, McGale P, Nisbet A, Dodwell D, Smith JT, et al. Cardiac dose from tangential breast cancer radiotherapy in the year 2006. Int J Radiat Oncol Biol Phys (2008) 72(2):501-7. doi:10.1016/j.ijrobp.2007.12.058

104. Kainz K, White J, Chen GP, Hermand J, England M, Li XA. Simultaneous irradiation of the breast and regional lymph nodes in prone position using helical tomotherapy. Br J Radiol (2012) 85(1018):e899-905. doi:10.1259/bjr/18685881

105. Feng M, Moran JM, Koelling T, Chughtai A, Chan JL, Freedman L, et al. Development and validation of a heart atlas to study cardiac exposure to radiation following treatment for breast cancer. Int J Radiat Oncol Biol Phys (2011) 79(1):10-8. doi:10.1016/j.ijrobp.2009.10.058

106. Kong FM, Klein EE, Bradley JD, Mansur DB, Taylor ME, Perez CA, et al. The impact of central lung distance, maximal heart distance, and radiation technique on the volumetric dose of the lung and heart for intact breast radiation. Int J Radiat Oncol Biol Phys (2002) 54(3):963-71. doi:10.1016/S0360-3016(02) 03741-0

107. Qi XS, Hu A, Wang K, Newman F, Crosby M, Hu B, et al. Respiration induced heart motion and indications of gated delivery for left-sided breast irradiation. Int J Radiat Oncol Biol Phys (2012) 82(5):1605-11. doi:10.1016/j.ijrobp.2011. 01.042

108. Evans SB, Panigrahi B, Northrup V, Patterson J, Baldwin DE, Higgins SA, et al. Analysis of coronary artery dosimetry in the 3-dimensional era: implications for organ-at-risk segmentation and dose tolerances in left-sided tangential breast radiation. Pract Radiat Oncol (2013) 3(2):e55-60. doi:10.1016/j.prro. 2012.06.007

109. Aznar MC, Korreman SS, Pedersen AN, Persson GF, Josipovic M, Specht L. Evaluation of dose to cardiac structures during breast irradiation. Br J Radiol (2011) 84(1004):743-6. doi:10.1259/bjr/12497075

110. Chung E, Corbett JR, Moran JM, Griffith KA, Marsh RB, Feng M, et al. Is there a dose-response relationship for heart disease with low-dose radiation therapy? Int J Radiat Oncol Biol Phys (2013) 85(4):959-64. doi:10.1016/j.ijrobp. 2012.08.002

111. Prabhakar R, Ganesh T, Rath GK, Julka PK, Sridhar PS, Joshi RC, et al. Impact of different CT slice thickness on clinical target volume for 3D conformal radiation therapy. Med Dosim (2009) 34(1):36-41. doi:10.1016/j.meddos.2007. 09.002

112. Topolnjak R, de Ruiter P, Remeijer P, van Vliet-Vroegindeweij C, Rasch C, Sonke JJ. Image-guided radiotherapy for breast cancer patients: surgical clips as surrogate for breast excision cavity. Int J Radiat Oncol Biol Phys (2011) 81(3):e187-95. doi:10.1016/j.ijrobp.2010.12.027

113. Shapiro CL, Hardenbergh PH, Gelman R, Blanks D, Hauptman P, Recht A, et al. Cardiac effects of adjuvant doxorubicin and radiation therapy in breast cancer patients. J Clin Oncol (1998) 16(11):3493-501.

Conflict of Interest Statement: The authors declare that the research was conducted in the absence of any commercial or financial relationships that could be construed as a potential conflict of interest.

Received: 14 July 2014; accepted: 30 October 2014; published online: 14 November 2014.

Citation: Beck RE, Kim L, Yue NJ, Haffty BG, Khan AJ and Goyal S (2014) Treatment techniques to reduce cardiac irradiation for breast cancer patients treated with breast-conserving surgery and radiation therapy: a review. Front. Oncol. 4:327. doi: 10.3389/fonc.2014.00327

This article was submitted to Radiation Oncology, a section of the journal Frontiers in Oncology.

Copyright (๑) 2014 Beck, Kim, Yue, Haffty, Khan and Goyal. This is an open-access article distributed under the terms of the Creative Commons Attribution License (CC $B Y)$. The use, distribution or reproduction in other forums is permitted, provided the original author(s) or licensor are credited and that the original publication in this journal is cited, in accordance with accepted academic practice. No use, distribution or reproduction is permitted which does not comply with these terms. 